\title{
Microbatch mixing: "Shaken not Stirred," a method for macromolecular microcrystal production for serial crystallography
}

Brian P. Mahon ${ }^{\mathrm{a}}$, Justin J. Kurian ${ }^{\mathrm{a}}$, Carrie L. Lomelino ${ }^{\mathrm{a}}$, Ian R. Smith ${ }^{\mathrm{b}}$, Lilien Socorro ${ }^{\mathrm{a}}$, Antonette Bennett ${ }^{\mathrm{a}}$, Alex M. Hendon ${ }^{\mathrm{a}}$, Paul Chipman ${ }^{\mathrm{a}}$, Daniel A. Savin ${ }^{\mathrm{b}}$, Mavis AgbandjeMcKenna $^{\mathrm{a}}$ and Robert McKenna ${ }^{\mathrm{a}, *}$

${ }^{\mathrm{a} D e p a r t m e n t ~ o f ~ B i o c h e m i s t r y ~ a n d ~ M o l e c u l a r ~ B i o l o g y, ~ U n i v e r s i t y ~ o f ~ F l o r i d a ~ C o l l e g e ~ o f ~ M e d i c i n e, ~}$ Gainesville, Florida 32610

${ }^{\mathrm{b}}$ Department of Chemistry, University of Florida, Gainesville, Florida 32611

*Corresponding Author. R.M. Telephone: (352) 392-5696; e-mail: rmckenna@ufl.edu.

\section{Supplemental Material}

Dynamic light scattering of hCA II microcrystals

Multi-angle dynamic light scattering (DLS) measurements were performed on an ALV/CGS-3 four-angle, compact goniometer system, which consisted of a $22 \mathrm{~mW}$ HeNe linear polarized laser operating at a wavelength of $\lambda=632.8 \mathrm{~nm}$ and scattering angles from $\theta=30-150^{\circ}$. Fluctuations in the scattering intensity were measured via an ALV/LSE-5004 multiple tau digital correlator, and analyzed by the intensity autocorrelation function $\left(g^{(2)}(\tau)\right) .^{32}$ The correlation functions were fit to a stretched exponential function (typical $\beta \sim 0.7$,) and the mutual diffusion coefficient was calculated through the relation

$$
\Gamma=q^{2} D_{m}
$$

where $\Gamma$ is the average decay rate of the autocorrelation function and $\mathrm{q}^{2}$ is the scalar magnitude of the scattering vector. The hydrodynamic radius $\left(R_{\mathrm{h}}\right)$ was calculated through the StokesEinstein equation 


$$
D_{m} \approx D_{o}=\frac{k_{B} T}{6 \pi \eta_{s} R_{h}}
$$

Where $k_{\mathrm{B}}$ is the Boltzmann constant, $\mathrm{T}$ is the absolute temperature, and $\eta_{\mathrm{s}}$ is the solvent viscosity. Samples were filtered through a $0.45 \mu \mathrm{m}$ PVDF filter (Millipore) directly into precleaned scattering cells prior to measurement.

\section{Supplement Figure S1.}

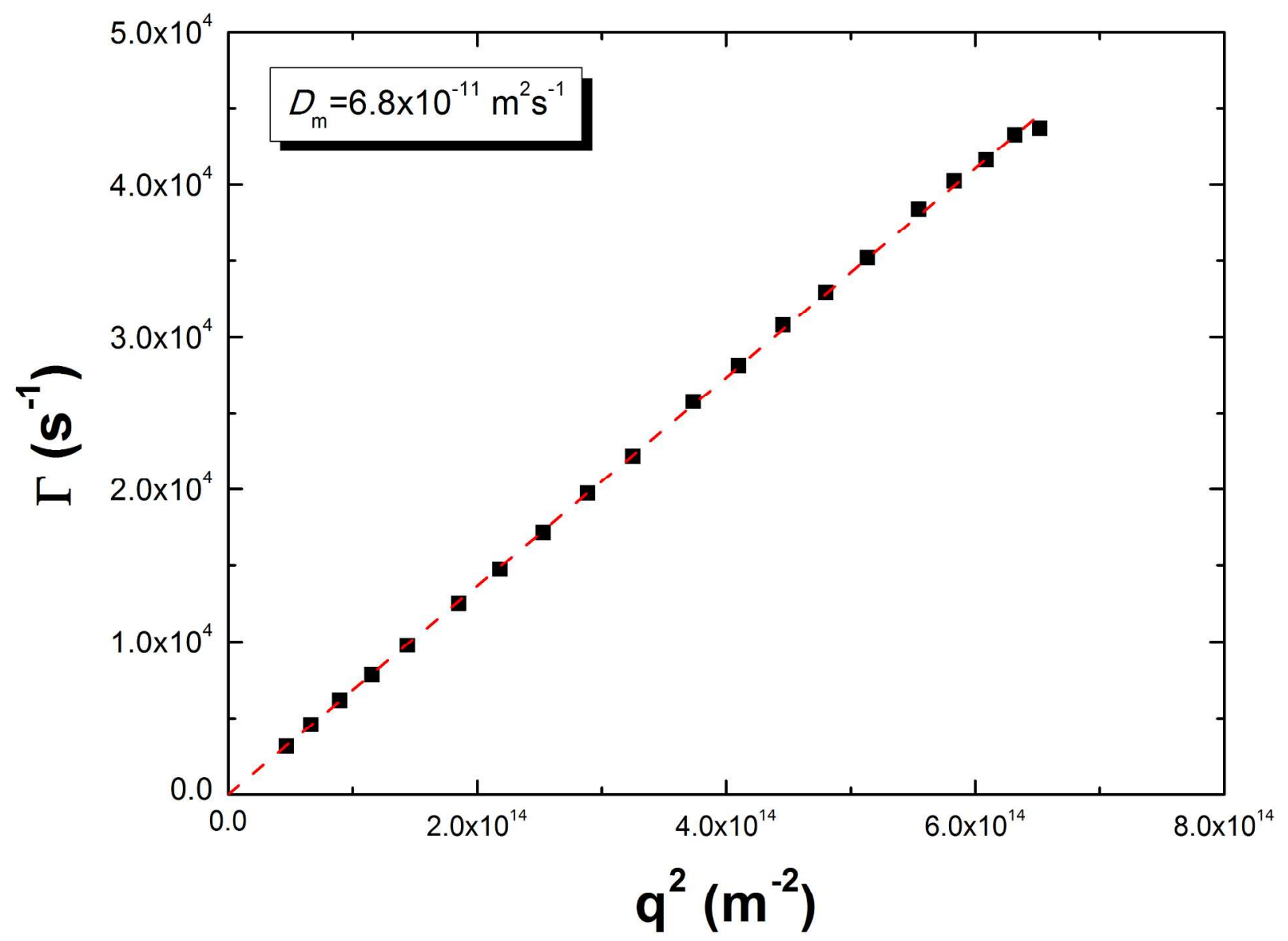

Gamma vs $\mathrm{q}^{2}$ plot for hCA II in $50 \mathrm{mM}$ Tris-Hcl at $\mathrm{pH}$ 7.8. The data follow a linear fit through the origin with a slope equal to the mutual diffusion coefficient $D_{\mathrm{m}}=6.8 \times 10^{-11} \mathrm{~m}^{2} \mathrm{~s}^{-1}$. Through the Stokes-Einstein relation, the hydrodynamic radius was calculated to be $R_{\mathrm{h}}=4 \mathrm{~nm}$. 


\section{Supplement Figure S2.}

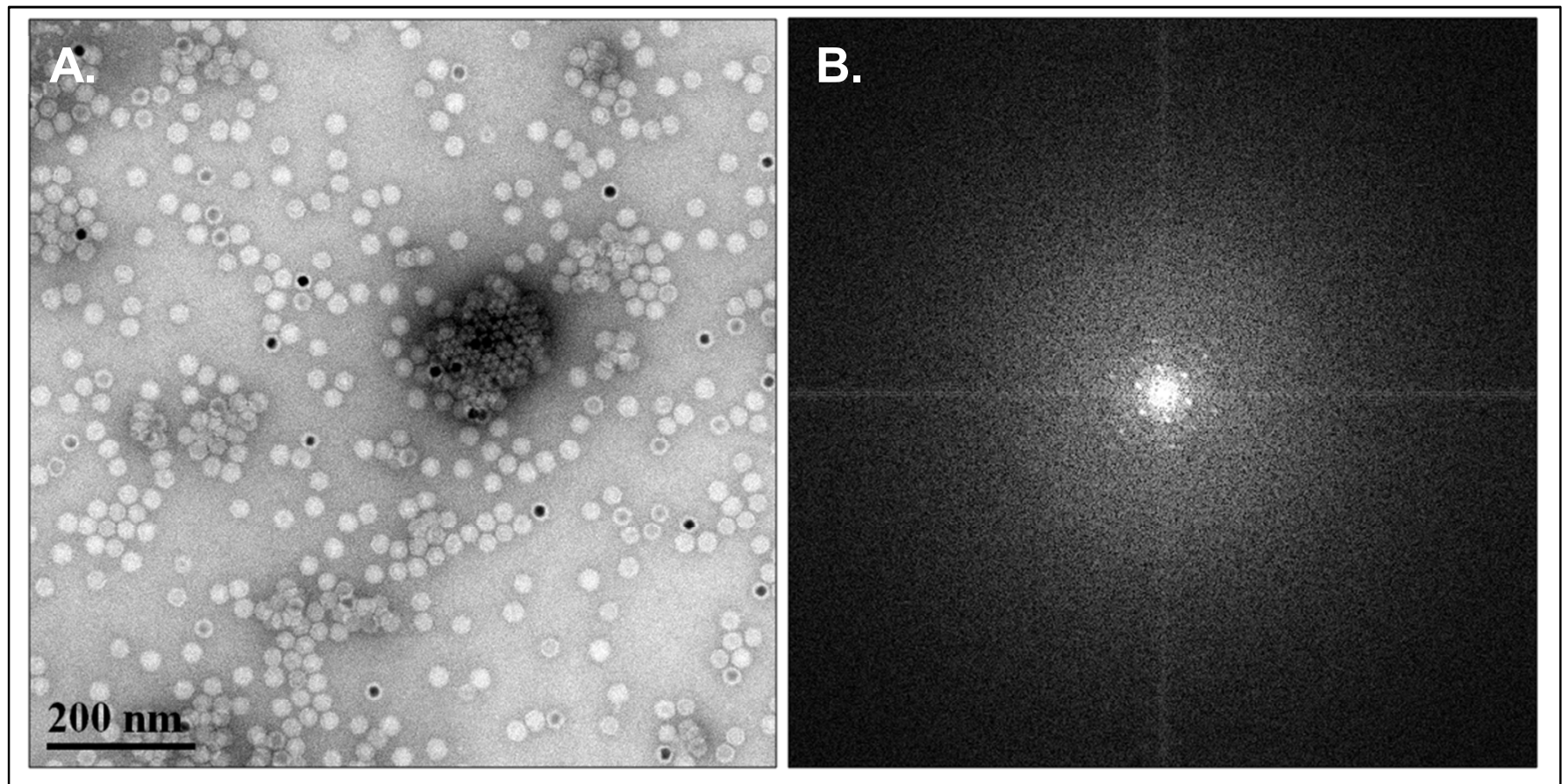

High-levels of stain penetration viewed in a thin crystal of AAV8, approximately $0.2 \mu \mathrm{m}$ in diameter. The corresponding FFT to this micrograph displayed a weak diffraction pattern, as would be typified for a crystal with an extremely low number of unit cells. The micrograph image also shows striations of stain in capsids that are directly associated with the crystalline state. Imaging via negative-stain EM may impact the morphology and resilience of the microcrystals, resulting in deformation or destruction of previously intact crystals due to desiccation and indirect thermal radiation at typical electron dosages. Once sample preparation for EM is optimized, future screening of microcrystals could be performed under cryogenic conditions (cryo-EM) after vitrifying the crystal slurry to verify morphology. 
